\title{
Effect of chronic renal failure medium on the ubiquitin-proteasome pathway of arterial muscle cells
}

\author{
YAO-QUAN ZHANG ${ }^{1}$, BING FENG ${ }^{2}$ and FA-HUAN YUAN ${ }^{2}$ \\ ${ }^{1}$ Department of Nephrology, The Affiliated Jiangyin Hospital of Southeast University Medical College, Jiangyin 214400; \\ ${ }^{2}$ Department of Nephrology, Xinqiao Hospital, Third Military Medical University, Chongqing 400037, P.R. China
}

Received August 9, 2012; Accepted December 18, 2012

DOI: $10.3892 / \mathrm{mmr} .2013 .1269$

\begin{abstract}
The ubiquitin-proteasome pathway (UPP) is involved in the occurrence and development of atherosclerosis through inhibitor of $\kappa \mathrm{B}(\mathrm{I} \kappa \mathrm{B})$ degradation which activates nuclear factor $-\kappa \mathrm{B}(\mathrm{NF}-\kappa \mathrm{B})$. However, the correlation between UPP and vascular complications of uramia remains unknown. The aim of the present study was to determine whether the UPP is activated in aortic smooth muscle cells (ASMCs) when cultured with uremic serum and to examine the role of the UPP on the dysfunction of ASMCs in uremia. ASMCs were cultured with pooled normal sera or chronic renal failure sera. The mRNA expression levels for ubiquitin (Ub) and Ub-activating enzyme (E1) were analyzed using reverse transcription PCR and levels of the ubiquitinated proteins $\mathrm{E} 1$ and $\mathrm{I} \kappa \mathrm{B} \alpha$ were measured using western blot analysis. The enzymatic activities of three $20 \mathrm{~S}$ proteasomes were examined using specific fluorogenic peptide substrates. Compared with normal serum, chronic renal serum increased E1 mRNA and protein expression of rabbit ASMCs (both $\mathrm{P}<0.01$ ). In addition, the mRNA expression of Ub also increased and the expression of I $\kappa \mathrm{B} \alpha$ was observed to decrease significantly (both $\mathrm{P}<0.01$ ). Ubiquitinated proteins in the normal and chronic renal failure groups were not found to be significantly different, but the activity of proteasomes increased significantly $(\mathrm{P}<0.01)$. Chronic renal failure medium induced the activation of the UPP in ASMCs.
\end{abstract}

\section{Introduction}

Cardiovascular disease is the leading cause of mortality in chronic renal failure (CRF), accounting for $~ 50 \%$ of mortalities $(1,2)$, wherein CRF-accelerated atherosclerosis is an important contributor. However, the pathogenesis is currently

Correspondence to: Professor Yao-quan Zhang, Department of Nephrology, The Affiliated Jiangyin Hospital of Southeast University Medical College, 163 Shoushan Road, Jiangyin 214400, P.R. China E-mail: yaoquanzhang@yeah.net

Key words: chronic renal failure, serum, smooth muscle cells, ubiquitin, proteasomes unclear. Therefore, analysis of the mechanism of the occurrence of CRF-accelerated atherosclerosis may aid reduction of cardiovascular disease incidence in patients with CRF and improve their prognosis and quality of life.

The ubiquitin-proteasome pathway (UPP) has been identified to be significantly activated in CRF patients. This may be closely associated with the degradation of muscle protein, as well as the occurrence of metabolic acidosis, malnutrition, micro-inflammation and other complications in patients with CRF (3-5). Thus, the UPP may be involved in the occurrence and development of atherosclerosis $(6,7)$ through degradation of inhibitor of $\kappa \mathrm{B}(\mathrm{I} \kappa \mathrm{B})$, leading to activation of nuclear factor- $\kappa \mathrm{B}(\mathrm{NF}-\kappa \mathrm{B})$.

Previous studies have reported that the UPP was activated in the aorta of rabbits with CRF and that MG-132 proteasome inhibitor treatment significantly inhibited NF- $\mathrm{NB}$ activity (8). However, the mechanism of UPP activation in aortic smooth muscle cells (ASMCs) under CRF is unclear. In the present study, rabbit ASMCs were cultured in vitro using CRF serum and changes in the UPP were observed to determine the mechanism of UPP expression in ASMCs under CRF conditions.

\section{Materials and methods}

Experimental animals. Twenty adult male New Zealand white rabbits, weighing $2.0 \pm 0.2 \mathrm{~kg}$, were randomly divided into two groups $(n=10)$. One group was used to construct the CRF animal model for serum collection and the other group was used for normal serum collection. Healthy male New Zealand white rabbits, weighing $0.5 \pm 0.2 \mathrm{~kg}$, were used for cell culture. These animals were provided by the Third Military Medical University Experimental Animal Center [license no.: SYXK (Chongqing) 2007-0012]. The study was approved by the ethics committee of Affiliated Jiangyin Hospital of Southeast University Medical College, Jiangyin, Jiangsu, China.

Serum collection. The rabbit CRF model was constructed as described previously (8). Briefly, rabbits were anesthetized with $2 \%$ pentobarbital sodium $(3 \mathrm{mg} / \mathrm{kg})$ through ear vein injection. Rabbits were fixed on the operating table in the lateral position. Rabbit hair on both sides of the rabbit kidney area was removed and the area was partially disinfected with $0.5 \%$ povidone-iodine. A longitudinal incision $(\sim 3 \mathrm{~cm}$ long) was made in the area of the left kidney and the abdominal 
Table I. Primer pairs.

\begin{tabular}{lllcc}
\hline Gene & Primer direction & \multicolumn{1}{c}{ Primer sequence } & Tm $\left({ }^{\circ} \mathrm{C}\right)$ & Product length (bp) \\
\hline Ub & Forward & 5'-TGGCCGTACTCTTTCTGA-3' & 60 & 127 \\
& Reverse & 5'-CTCCACTTCCAGGGTGAT-3' & & 287 \\
E1 & Forward & 5'-AGCCTA ATGGTGAGGAGATG-3' & 57 & \multirow{2}{*}{416} \\
\multirow{3}{*}{$\beta$-actin } & Reverse & 5'-TCAGCGGATGGTGTATCG-3' & & \\
& Forward & 5'-GAGCTACGAGCTGCCTGACG-3' & $57-62$ & \\
& Reverse & 5'-CCTAGAAGCATTTGCGGTGG-3' & & \\
\hline
\end{tabular}

cavity was opened to expose the left kidney. The perirenal fat capsule was separated and the renal artery and its branches were isolated, revealing three branches of the renal artery. Two branches of arteries supplying the lower pole received ligation with the 0 line, $\sim 2 / 3$ of the left kidney immediately became pale and then turned purple. The left kidney was then returned to its usual location after $1 \mathrm{~min}$. The incision was sutured. A longitudinal incision ( $2 \mathrm{~cm}$ long) was made in the right kidney area to open the abdominal cavity, the right kidney was exposed and the right renal pedicle was isolated. The renal pedicle was ligated with line 4 and the right kidney was removed. When intraoperative and field bleeding ended, the incision was layer sutured to close the abdominal cavity. Following 12 weeks, the animals were anesthetized and their abdominal cavities were cut open. Inferior vena venous blood was drawn and the serum was separated from the blood, mixed, filtrated using a $0.22-\mu \mathrm{m}$ microporous membrane and stored at $-70^{\circ} \mathrm{C}$.

Rabbit ASMCs primary culture and identification. As described previously (9), the rabbit aorta was extracted under sterile conditions, the outer membrane was carefully peeled back and the inner membrane was removed and cut into $1 \times 1-\mathrm{mm}$ sections. Aortic SMCs (ASMCs) were cultured in DMEM/F12 supplemented with $20 \%$ newborn calf serum and $1 \%$ penicillin-streptomycin at $37^{\circ} \mathrm{C}$ in a $95 \%$ air $5 \% \mathrm{CO}_{2}$ incubator. When the cells reached $80 \%$ confluence, they were digested using trypsin, passaged and then inoculated into culture bottles at specific densities. Cells from passages 3-5 were used in the present study. SMCs were identified using morphological observations and $\alpha$-SM-actin immunofluorescence.

Reverse transcription PCR (RT-PCR). Cells were cultured in serum-free media and synchronized in the $\mathrm{G}_{0}$ phase. Following addition of $10 \%$ normal or CRF-stimulated serum, total RNA was extracted according to the manufacturer's instructions. The RNA extraction kit was purchased from TIANDZ (Mianyang, China). The reverse transcriptase-polymerase chain reaction (PCR) kit was purchased from BioDev (Beijing, China). RT-PCR conditions were as follows: pre-denaturation at $94^{\circ} \mathrm{C}$ for $5 \mathrm{~min}$, denaturation at $94^{\circ} \mathrm{C}$ for $40 \mathrm{sec}$, annealing at primer-specific temperatures for $40 \mathrm{sec}, 72^{\circ} \mathrm{C}$ for $1 \mathrm{~min}$ and 32 cycles and termination at $72^{\circ} \mathrm{C}$ for $5 \mathrm{~min}$. The primer sequences are presented in Table I. PCR products were identified using agarose electrophoresis, staining and imaging. The density ratio of the target gene fragment and the internal reference $\beta$-actin represented relative mRNA expression.
Western blot analysis. Following cell culture in serum-free media and synchronization in the $\mathrm{G}_{0}$ phase, cells were incubated in $10 \%$ normal or CRF rabbit serum for $24 \mathrm{~h}$. Next, total cellular protein was extracted and measured. Protein samples $(20 \mu \mathrm{g})$ were used for $10 \%$ SDS-PAGE, transferred to film and blocked in 5\% nonfat dry milk at room temperature for $2 \mathrm{~h}$. Antibodies against ubiquitin (Ub) (1:1,000), E1 (1:2,000), IкB $\alpha(1: 400)$ and $\beta$-actin $(1: 1,000)$ were added and the samples were incubated at $4^{\circ} \mathrm{C}$ overnight. HRP-labeled IgG secondary antibodies $(1: 10,000)$ were added and the samples were incubated at room temperature for $1 \mathrm{~h}$. The membrane was washed and color light-emitting substrate was added to the membrane, which was then analyzed through gel imaging.

Proteasome activity assay. Cells were cultured in serum-free media and synchronized in the $\mathrm{G}_{0}$ phase. Next, cells were interfered by $10 \%$ normal or CRF serum for $24 \mathrm{~h}$. Cells were washed with ice-cold $0.01 \mathrm{~mol} / \mathrm{l} \mathrm{PBS}$, scraped gently and centrifuged at $1,000 \mathrm{x} \mathrm{g} / \mathrm{min}$ for $5 \mathrm{~min}$ at $4^{\circ} \mathrm{C}$. The cell pellet was washed with $1 \mathrm{X}$ PBS twice and transferred to an EP tube, to which $1 \mathrm{ml}$ of $20 \mathrm{mmol} / \mathrm{l}$ Tris ( $\mathrm{pH}$ 7.6) was added. The EP tube was placed in liquid nitrogen for $5 \mathrm{~min}$ and then placed at $37^{\circ} \mathrm{C}$ for $5 \mathrm{~min}$. Protein concentration was determined using the Bradford method. Total cellular protein extracts $(20 \mu \mathrm{g})$ were used for each group. The extract was incubated with the proteasome-specific substrate $\mathrm{S}, \mathrm{Z}$ and $\mathrm{B}$ (substrate S: N-succinyl-Leu-Leu-Val-Tyr-7-amido-4-methyleoumarin, molecular weight 763.9, excitation/emission wavelength 380/440 nm, chymotrypsin-like activity; substrate Z: Z-Leu-Leu-Glu- $\beta$-naphthylamide, molecular weight 632.8 , excitation/emission wavelength $335 / 410 \mathrm{~nm}$, peptide-Valley aminoacyl-peptide hydrolase activity; and substrate B: Boc-Gln-Ala-Arg-7-amido-4-methylcoumarin hydrochloride, molecular weight 667.2 , excitation/emission wavelength $380 / 440 \mathrm{~nm}$, trypsin activity) at $37^{\circ} \mathrm{C}$ for $30 \mathrm{~min}$ (final substrate concentration, $10 \mu \mathrm{mol} / 1$; pH 8.0; Hepes buffer, $500 \mu \mathrm{l}$ ). The reaction was terminated by adding the same volume of ice-cold ethanol and $3 \mathrm{ml}$ deionized water. Finally, fluorescence was measured using a fluorescence microplate reader and the absorbance values reflected the activity. Samples of each group were formed of three parallel tubes. Experiments were repeated three times.

Statistical analysis. Statistical analyses were performed using SPSS 10.0 software (SPSS, Inc., Chicago, IL, USA) and data are expressed as mean $\pm \mathrm{SD}$. Groups were compared using 
Table II. Biochemical index for the pooled sera of CRF and normal rabbits.

\begin{tabular}{lcccccccrr}
\hline Rabbits & $\begin{array}{c}\mathrm{BUN} \\
(\mathrm{mmol} / \mathrm{l})\end{array}$ & $\begin{array}{c}\mathrm{SCr} \\
(\mu \mathrm{mol} / \mathrm{l})\end{array}$ & $\begin{array}{c}\mathrm{K}^{+} \\
(\mathrm{mmol} / \mathrm{l})\end{array}$ & $\begin{array}{c}\mathrm{Na}^{+} \\
(\mathrm{mmol} / \mathrm{l})\end{array}$ & $\begin{array}{c}\mathrm{Cl}^{-} \\
(\mathrm{mmol} / \mathrm{l})\end{array}$ & $\begin{array}{c}\mathrm{CO}_{2} \mathrm{CP} \\
(\mathrm{mmol} / \mathrm{l})\end{array}$ & $\begin{array}{c}\mathrm{Ca}^{2+} \\
(\mathrm{mmol} / \mathrm{l})\end{array}$ & $\begin{array}{c}\mathrm{P}^{3+} \\
(\mathrm{mmol} / \mathrm{l})\end{array}$ & $\begin{array}{c}\mathrm{iPTH} \\
(\mathrm{pg} / \mathrm{ml})\end{array}$ \\
\hline Normal & 7.65 & 76.60 & 4.80 & 135.10 & 98.32 & 24.00 & 2.07 & 1.13 \\
CRF & 25.75 & 350.80 & 5.80 & 145.20 & 101.25 & 22.00 & 1.62 & 1.26 & 23.2 \\
\hline
\end{tabular}

CRF, chronic renal failure.
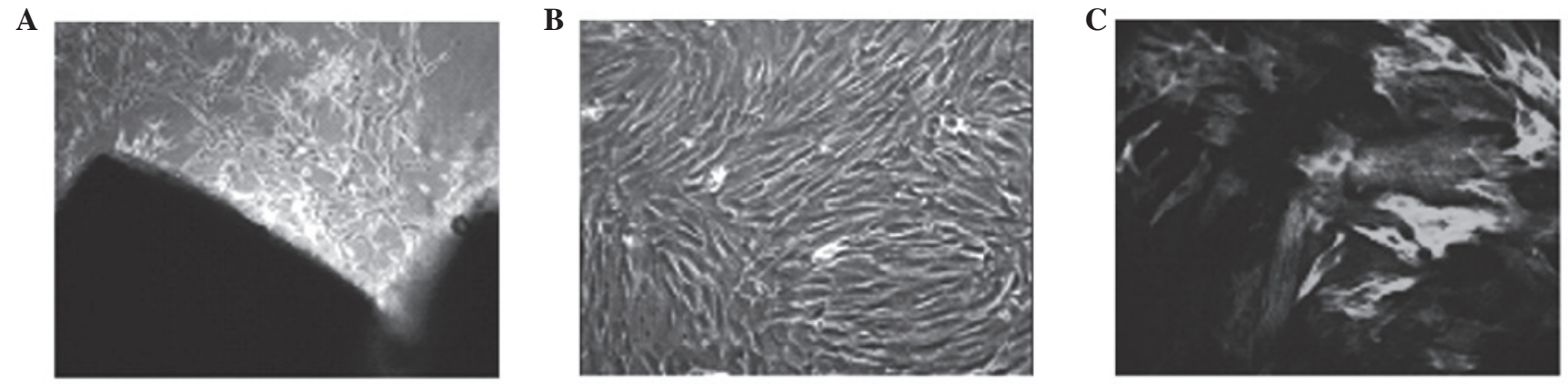

Figure 1. ASMC morphology characterization. Images reveal rabbit ASMCs (A) attached on culture day 5 (magnification, x100); (B) exhibited 'peak'-, 'valley'-like growth (magnification, x100); and (C) were $\alpha$-SM-positive (FITC immunofluorescence. Magnification, x400). ASMC, aortic smooth muscle cell.

Table III. Effect of CRF serum on aortic endothelial cells, proteasome $20 \mathrm{~S}$ subunit activity (mean $\pm \mathrm{SD}, \mathrm{n}=3$ ).

\begin{tabular}{lccc}
\hline & \multicolumn{3}{c}{ Fluorescence absorbance value (A) } \\
\cline { 2 - 4 } Group & Substrate $S$ & Substrate Z & Substrate B \\
\hline Serum-free & $37.47 \pm 1.14$ & $90.67 \pm 2.97$ & $70.10 \pm 1.77$ \\
Normal serum & $50.50 \pm 2.75^{\mathrm{a}}$ & $127.13 \pm 4.18^{\mathrm{a}}$ & $101.10 \pm 5.19^{\mathrm{a}}$ \\
CRF serum & $90.57 \pm 5.85^{\mathrm{a}, \mathrm{b}}$ & $229.30 \pm 6.93^{\mathrm{a}, \mathrm{b}}$ & $192.73 \pm 5.61^{\mathrm{a}, \mathrm{b}}$ \\
\hline
\end{tabular}

${ }^{\mathrm{a}} \mathrm{P}<0.01$, vs. serum-free; ${ }^{\mathrm{b}} \mathrm{P}<0.01$, vs. normal serum. $\mathrm{CRF}$, chronic renal failure.

ANOVA and further pairwise comparisons were performed using an LSD t-test. $\mathrm{P}<0.05$ was considered to indicate a statistically significant difference.

\section{Results}

Cell morphology and biochemical index. Cells were isolated and grew from homogenized aorta following 3-5 days. The majority of the cells were elongated spindle-shaped and fusion revealed typical 'peak'- and 'valley'-like growth states. $\alpha$-SM immunofluorescence staining was positive and a filament-like structure was visible in the cytoplasm (Fig. 1). Results of the biochemical analysis of CRF and control rabbits are presented in Table II.

$U b$ and E1 mRNA expression. Compared with normal serum, $10 \%$ CRF serum was found to increase Ub $(0.16 \pm 0.03$ vs. $0.26 \pm 0.02)$ and E1 (0.18 \pm 0.02 vs. $0.89 \pm 0.02)$ mRNA levels in ASMCs significantly ( $\mathrm{P}<0.01$; Fig. 2).

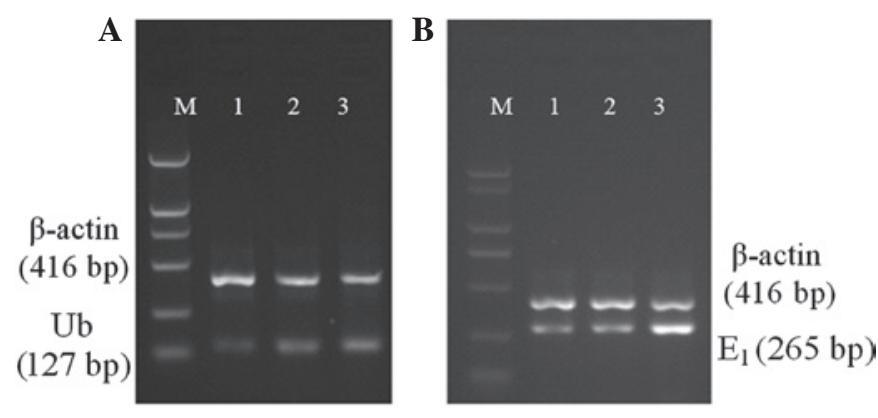

Figure 2. Effect of CRF serum on AMSC expression of (A) Ub and (B) E1 mRNA. M, Marker; lane 1, no serum; lane 2, 10\% normal serum; lane 3, $10 \%$ CRF serum. ASMC, aortic smooth muscle cell; Ub, ubiquitin; E1, Ub-activating enzyme; CRF, chronic renal failure.

E1, I $\kappa B \alpha$ and ubiquitinated protein expression. Compared with normal serum, $10 \%$ CRF serum was observed to significantly increase E1 $(2.63 \pm 0.15$ vs. $3.60 \pm 0.20)$ and reduce $\mathrm{I} \kappa \mathrm{B} \alpha$ protein expression $(0.81 \pm 0.03$ vs. $0.12 \pm 0.02)$ of ASMCs (both $\mathrm{P}<0.01$ ), but had no significant effect on expression of ubiquitinated proteins $(12.76 \pm 0.42$ vs. $11.12 \pm 0.46 ; \mathrm{P}>0.05$; Fig. 3).

Proteasome activity. Following $24 \mathrm{~h}$ incubation with $10 \%$ normal and CRF serum, SMC proteasome activity increased. This effect was found to be significantly higher in samples in CRF serum $(\mathrm{P}<0.01$, Table III).

\section{Discussion}

Atherosclerosis is a chronic inflammatory response in vascular cells. Causative agents act on endothelial cells repeatedly, making the cells appear dysfunctional, which triggers inflammatory cytokine expression and consequently, the 


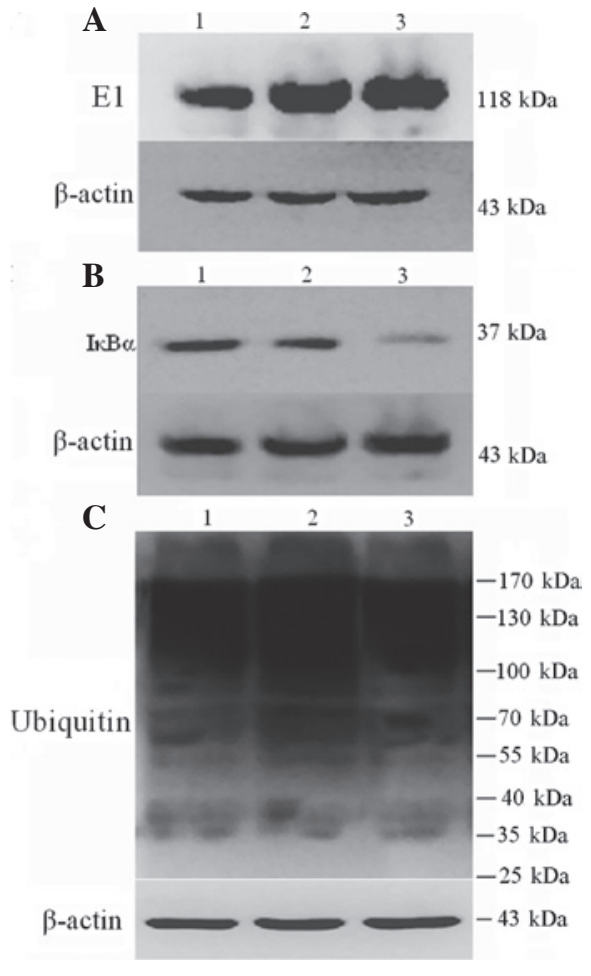

Figure 3. Effect of CRF serum on E1, I $\mathrm{B} \alpha$ and $\mathrm{Ub}$ expression of SMCs. (A) E1; (B) IкB $\alpha$; and (C) ubiquitin. Lane 1, serum-free; lane 2, 10\% normal serum; lane 3, 10\% CRF serum. CRF, chronic renal failure; E1, Ub-activating enzyme; Ub, ubiquitin; I $\kappa \mathrm{B} \alpha$, inhibitor of $\kappa \mathrm{B} \alpha$.

atherosclerosis dynamic link. Abnormal proliferation of SMCs is key to atherosclerosis development $(10,11)$.

The middle vessel wall is composed primarily of ASMCs, for which there are shrinkage and synthesis types. The former stimulates chemical and mechanical contraction, whereas the latter is primarily involved in the secretion of the extracellular matrix and the synthesis of vasoactive substances, as well as cell division and proliferation under growth factor stimulation involved in the formation and damage repair of the vessel wall (11). During atherosclerosis, the activation of endothelial cells triggers a conversion in the SMC phenotype from contractile to synthetic and the cells migrate to the intima under the effect of various factors. Abnormal proliferation occurs, which involves foam cell accumulation and the formation of fibrous and atherosclerotic plaques (12).

Previous studies on the SMC proliferation mechanism and prevention have reported that the inhibition of only one factor cannot suppress the formation of lesions completely. Therefore, the final common pathway for the effective prevention of vascular proliferative disease may be achieved by regulating cell proliferation, differentiation and migration.

The UPP is present in all eukaryotic cells. In addition to $\mathrm{Ub}$ expression, the pathway also includes the expression of E1, ubiquitin-conjugating enzyme (E2), ubiquitin ligases (E3) and the $26 \mathrm{~S}$ proteasome. UPP selectively degrades intracellular ubiquitination proteins using the proteasome. Thus, UPP not only destroys old damaged proteins, but is also involved in regulating a variety of important life processes (13-15), particularly through degradation of intracellular signaling pathways inhibitors and/or activators.
The UPP is the most important mechanism for regulation of the IKK/NF- $\kappa \mathrm{B}$ signaling pathway activation. To date, hundreds of forms of the E3 ligase have been identified. Recognition and binding of proteins and targets are specific and the tissue distribution of proteins are different. Previous studies have also found a variety of proteasome subtypes, which may play major roles in various pathophysiologies $(16,17)$. Interfering with blood cell-specific UPP activation, thereby inhibiting the proliferation of local tissue response to chronic inflammation, may be a promising approach in the clinical development of specific drugs.

In the present study, following CRF serum stimulation, $\mathrm{Ub}$ and E1 mRNA upregulation, as well as E1 protein expression in ASMCs, increased, but ubiquitinated protein levels were not found to be significantly altered. Protein ubiquitination is a prerequisite for UPP activation. Two hypotheses may account for the insignificant change in ubiquitination: i) degradation was not significant; or ii) the increase in proteasomal activity was compensated by degrading the increased pathological proteins.

The 26S proteasome is the final location of target protein degradation. This proteasome is a huge multi-subunit protease complex, primarily composed of two ring-shaped $19 \mathrm{~S}$ regulatory subunits and a $20 \mathrm{~S}$ catalytic subunit. A 20S subunit consists of four rings, including $\alpha$ and $\beta$ rings constituted by seven homologous $\alpha$ subunits and seven homologous $\beta$ subunits. Active sites are located in the hollow center of the cylindrical 20S structure and the N-terminal threonine of the $\beta$ subunit functions as a protease catalytic center, prominent in the barrel cavity. Only three of seven $\beta$-subunits have catalytic activity, namely, trypsin-, chymotrypsin- and cysteine protease-like. These activities cleave carboxy-terminal alkaline, hydrophobic or aromatic and acidic amino acid residues, thus degrading the substrate protein into small peptides (18).

To identify UPP activation signaling pathways, the activity of three 20S proteasome subunits of SMCs were examined. The activities of these enzymes were significantly higher compared with the control group. Carbó et al (19) studied human umbilical vein endothelial cells stimulated by uremic serum using a proteomic method. The authors found that levels of the proteasome subunit $\beta$ type 4 precursor and the proteasome activator complex subunit 3 expression increased, consistent with results in the present study. These observations indicate that CRF serum induced vascular cell UPP activation.

Degradation of ubiquitinated IкB is an important step in regulation of NF- $\mathrm{kB}$ activation. The present study found that CRF serum stimulation significantly reduced ASMC expression of I $\kappa$ B mRNA and protein, implying that UPP may be involved in the activation of the CRF serum-induced ASMC inflammatory response. Further studies are required to determine whether regulation of the NF- $\mathrm{kB}$ signaling pathway by UPP activation inhibits proliferation of the SMC inflammatory response and improves SMC function. In summary, CRF serum stimulation activates UPP in ASMCs, thereby affecting regulation of the NF- $\kappa B$ signaling pathway. These results are likely to provide theoretical and experimental insight to aid research into the prevention and treatment of atherosclerosis CRF. 


\section{References}

1. Locatelli F, Pozzoni P, Tentori F and del Vecchio L: Epidemiology of cardiovascular risk in patients with chronic kidney disease. Nephrol Dial Transplant 18: 2-9, 2003.

2. Hou FF, Ma ZG, Mei CL, et al: Epidemiology of cardiovascular risk in Chinese chronic kidney disease patients. Zhonghua Yi Xue Za Zhi 85: 753-759, 2005 (In Chinese).

3. Mitch WE, Du J, Bailey JL and Price SR: Mechanisms causing muscle proteolysis in uremia: the influence of insulin and cytokines. Miner Electrolyte Metab 25: 216-219, 1999.

4. Price SR, Du JD, Bailey JL and Mitch WE: Molecular mechanisms regulating protein turnover in muscle. Am J Kidney Dis 37 (Suppl 2): 112-114, 2001.

5. Mitch WE: Robert H Herman Memorial Award in Clinical Nutrition Lecture, 1997. Mechanisms causing loss of lean body mass in kidney disease. Am J Clin Nutr 67: 359-366, 1998.

6. Fukai T: Targeting proteasome worsens atherosclerosis. Circ Res 101: 859-861, 2007.

7. Herrmann J, Soares SM, Lerman LO and Lerman A: Potential role of the ubiquitin-proteasome system in atherosclerosis: aspects of a protein quality disease. J Am Coll Cardiol 51: 2003-2010, 2008.

8. Feng B, Zhang Y, Mu J, et al: Preventive effect of a proteasome inhibitor on the formation of accelerated atherosclerosis in rabbits with uremia. J Cardiovasc Pharmacol 55: 129-138, 2010.

9. Tao R, Lu L, Zhang R, Hu J, Ni J and Shen W: Triptolide inhibits rat vascular smooth muscle cell proliferation and cell cycle progression via attenuation of ERK1/2 and Rb phosphorylation. Exp Mol Pathol 90: 137-142, 2011.

10. Little PJ, Ivey ME and Osman N: Endothelin-1 actions on vascular smooth muscle cell functions as a target for the prevention of atherosclerosis. Curr Vasc Pharmacol 6: 195-203, 2008.
11. Chung SW, Park JW, Lee SA, Eo SK and Kim K: Thrombin promotes proinflammatory phenotype in human vascular smooth muscle cell. Biochem Biophys Res Commun 396: 748-754, 2010.

12. Newby AC: Matrix metalloproteinases regulate migration, proliferation and death of vascular smooth muscle cells by degrading matrix and non-matrix substrates. Cardiovasc Res 69: 614-624, 2006.

13. Murata T and Shimotohno K: Ubiquitination and proteasomedependent degradation of human eukaryotic translation initiation factor 4E. J Biol Chem 281: 20788-20800, 2006.

14. Murray AW: Recycling the cell cycle: cyclins revisited. Cell 116: 221-234, 2004.

15. Ciechanover A and Iwai K: The ubiquitin proteolytic system: from an idea to the patient bed. Proc Am Thorac Soc 3: 21-31, 2006.

16. Gomes AV, Young GW, Wang Y, et al: Contrasting proteome biology and functional heterogeneity of the $20 \mathrm{~S}$ proteasome complexes in mammalian tissues. Mol Cell Proteomics 8: 302-315, 2009

17. Drews O, Wildgruber R and Zong C: Mammalian proteasome subpopulations with distinct molecular compositions and proteolytic activities. Mol Cell Proteomics 6: 2021-2031, 2007.

18. Groll M, Ditzel L, Löwe J, et al: Structure of the 20S proteasome from yeast at 2.4 A resolution. Nature 386: 463-471, 1997.

19. Carbó C, Arderiu G, Escolar G, et al: Differential expression of proteins from cultured endothelial cells exposed to uremic versus normal serum. Am J Kidney Dis 51: 603-612, 2008. 